\title{
The Natural History of Spontaneously Occurred Endometriosis in Cynomolgus Monkeys by Monthly Follow-Up Laparoscopy for Two Years
}

\author{
Kaori Hayashi, ${ }^{1}$ Misako Nakayama, ${ }^{2}$ Chizuru Iwatani, ${ }^{3}$ Hideaki Tsuchiya, ${ }^{3}$ \\ Shinichiro Nakamura, ${ }^{3}$ Kosuke Nonoguchi, ${ }^{4}$ Yasushi Itoh, ${ }^{2}$ Shunichiro Tsuji, ${ }^{1}$ \\ Hirohito Ishigaki, ${ }^{2}$ Takahide Mori, ${ }^{5}$ Takashi Murakami ${ }^{1}$ and \\ Kazumasa Ogasawara ${ }^{2}$
}

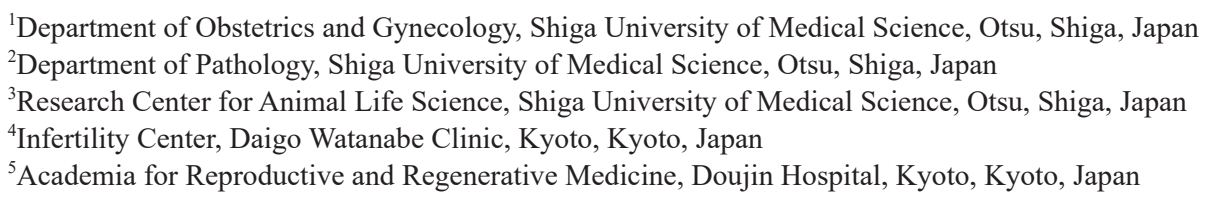

Endometriosis, a disease in which endometrial tissue proliferates outside the uterus, is a progressive disease that affects women in reproductive age. It causes abdominal pain and infertility that severely affects the quality of life in young women. The mechanism of the onset and development of endometriosis has not been fully elucidated because of the complex mechanism involved in the disease. Nonhuman primates have been used to study the pathogenesis of spontaneous endometriosis because of their gynecological and anatomical similarities to humans. To reveal the natural history of endometriosis in cynomolgus monkeys, we selected 11 female cynomolgus monkeys with spontaneous endometriosis and performed monthly laparoscopies, mapping endometriotic lesions and adhesions up to two years. At the initial laparoscopy, endometriotic lesions were exclusively found in the vesicouterine pouch in $45.4 \%(5 / 11)$ of the monkeys and spread to the Douglas' pouch over time. Appearance of small de novo lesions and disappearance of some of the small lesions were observed in $100 \%(11 / 11)$ and $18.2 \%(2 / 11)$ of the monkeys, respectively. Endometriosis developed in all monkeys, and the speed of progression varied greatly among individuals that could be attributed to the degree or frequency of retrograde menstruation and genetic factors; these findings support the similarities between humans and monkeys, thus verifying the value of this nonhuman primate model. Finding reliable quantification markers and unravelling the underlying factors in correlation with the spatiotemporal development of the disease using a nonhuman primate model would be useful for the better management of endometriosis in humans.

Keywords: cynomolgus monkey; endometriosis; laparoscopy; natural history of endometriosis; spontaneous endometriosis

Tohoku J. Exp. Med., 2020 August, 251 (4), 241-253.

\section{Introduction}

Endometriosis, a disease of unknown etiology defined as the presence of endometrial tissue outside the uterus, is a progressive disease that affects $5 \%$ to $10 \%$ of women in reproductive age (Bulun 2009). It causes abdominal pain and infertility that severely affects the quality of life in young women. Hormonal treatment and surgical resection of the lesion are performed to alleviate symptoms, but there is no standard treatment to cure the disease (Olive and Pritts 2001; Bizzarri et al. 2014). The mechanism of the onset and development of endometriosis has not been fully elucidated, due to the complex mechanism involved (e.g., inflammatory status, hormornal status, genetic factors and epigenetic changes) and lack of reliable quantification markers of the disease (Bulun 2009). Laparoscopic obser-

Received April 21, 2020; revised and accepted June 29, 2020. Published online July 22, 2020; doi: 10.1620/tjem.251.241.

Correspondence: Misako Nakayama, Department of Pathology, Shiga University of Medical Science, Seta-tsukinowa cho, Otsu, Shiga 520-2192, Japan.

e-mail: miema@belle.shiga-med.ac.jp

(C)2020 Tohoku University Medical Press. This is an open-access article distributed under the terms of the Creative Commons Attribution-NonCommercial-NoDerivatives 4.0 International License (CC-BY-NC-ND 4.0). Anyone may download, reuse, copy, reprint, or distribute the article without modifications or adaptations for non-profit purposes if they cite the original authors and source properly.

https://creativecommons.org/licenses/by-nc-nd/4.0/ 
vation, the most reliable method for assessing the presence and distribution of endometriotic lesions, is performed in limited patients such as patients unresponsive to hormonal treatment and patients with infertility requiring detailed evaluation. However, it is uncommon to observe the lesion by laparoscopy repeatedly and the spatiotemporal development of the disease is largely unknown. Thus, repeated observation by laparoscopy is required for elucidating the mechanism of the onset and development of endometriosis.

Animal models of endometriosis are required to pursue the pathogenesis and evaluate the effects of therapeutic intervention. Of note, mice do not menstruate and their oviducts are not open to the pelvic cavity (Maronpot 1999). Therefore, endometriosis models in mice may not reflect the pathogenesis of human endometriosis, and it may be difficult to extrapolate the findings directly to human patients. In contrast, nonhuman primates have been used to study the pathogenesis of spontaneous endometriosis due to their gynecological and anatomical similarities to humans; i.e., they have menstrual cycles and spontaneous endometriosis, and the fimbria that lies in close apposition to the ovary is open to the pelvic cavity (Eddy and Laufe 1983; Story and Kennedy 2004; D'Hooghe et al. 2009; Braundmeier and Fazleabas 2009; Yamanaka et al. 2012). Most of the studies have been carried out using baboons (D’Hooghe et al. 1991, 1992, 1996; Cornillie et al. 1992; Kyama et al. 2007; Afshar et al. 2013), and a few studies have been carried out using cynomolgus monkeys (Ami et al. 1993; Nishimoto-Kakiuchi et al. 2016, 2018) and rhesus monkeys (Assaf and Miller 2012; Simmons 2016). Although baboons have served as an established model of spontaneous endometriosis, breeding and handling of cynomolgus monkeys are generally easier than those of baboons. This means that cynomolgus monkeys have potential values to be used more widely for the study of endometriosis together with other gynecological studies in monkeys (Hester et al. 2010; Duffy and VandeVoort 2011; Kittivanichkul et al. 2016). Thus, cynomolgus monkeys would be one of the most potent animal models to analyze the pathogenesis and to develop treatment of endometriosis.

The natural history of endometriosis in cynomolgus monkeys has not been elucidated, although cynomolgus monkeys could be a clinically relevant experimental model of spontaneous endometriosis. Indeed, 614 female monkeys were screened with CA125 serum levels, palpation of the abdomen, and fecal abnormalities (Nishimoto-Kakiuchi et al. 2018). The selected 29 monkeys had relatively advanced endometriosis, and 8 of them were followed twice or three times by laparoscopy up to 7 months (NishimotoKakiuchi et al. 2018). In the present study, to reveal the natural history of endometriosis in cynomolgus monkeys, we performed monthly laparoscopies and mapped endometriosis lesions and adhesions in detail up to two years in 11 monkeys.

\section{Materials and Methods}

Animals

During 2014 July-August, 219 cynomolgus monkeys (Macaca fascicularis) (113 monkeys between 4-9 years old and 106 monkeys over 10 years old) reared at the Research Center for Animal Life Science at Shiga University of Medical Science underwent laparoscopy to find the prevalence of spontaneous endometriosis. Five monkeys were diagnosed as having endometriosis by laparoscopy. Apart from those five monkeys, during 2014 April-2016 March, 11 female cynomolgus monkeys were diagnosed as having endometriosis during regular laparoscopic examinations for breeding. The origins of monkeys were Vietnam $(n=5)$, China $(\mathrm{n}=2)$, Philippines $(\mathrm{n}=1)$ or born by artificial breeding in our institute $(n=3)$. The animals are distinguished by identification numbers and their backgrounds are shown in Table 1. They were followed with monthly laparoscopies for 24 months (monkeys \#1-6, 8 and 11), 21 months (monkey \#9), 18 months (monkey \#10) and 11 months (monkey \#7). The monkeys were singly caged and were free from herpes B virus, hepatitis E virus, Mycobacterium tuberculosis, Shigella spp., Salmonella spp., and Entamoeba histolytica. Food, drinking water and housing were provided as described previously (Nakayama et al. 2013). Temperature, humidity and light/dark cycles of the animal room were $25 \pm 2{ }^{\circ} \mathrm{C}, 50 \pm 5 \%$ and 12 hours, respectively. To ensure that monkeys were not suffering from continuing monthly laparoscopies, body weights were monitored every month. A paired t-test was performed by GraphPad Prism version 8.3.0. to analyze statistical differences between weights of the first and last laparoscopy.

\section{Laparoscopy}

Laparoscopy was performed by the same investigator with minimal invasiveness, and efforts were made to minimize the suffering of monkeys. Anesthesia was performed with ketamine $(5 \mathrm{mg} / \mathrm{kg})$ and xylazine $(1 \mathrm{mg} / \mathrm{kg})$. A trocar ( $3 \mathrm{~mm}$ ) was placed in the midline, below the umbilicus, to insert the laparoscope (LA-6500, Machida Endoscope Co., Ltd., Chiba, Japan). Another trocar was placed in the right flank to insert an operating rod. In order to create a workspace for the operating rod and laparoscope, the monkey's abdomen was inflated with approximately $200 \mathrm{~mL}$ of filtered air when inserting the trocars. The laparoscope was connected to a charge-coupled device camera, and images were displayed and recorded in a hard disk drive (SHIMIZU Laboratory Supplies Co., Ltd., Kyoto, Japan) in the operation room. Observation time was approximately 3-5 minutes, and the whole procedure was less than 10 minutes. Each lesion of endometriosis was assessed on the basis of observation of the pelvic cavity by laparoscopy and review of recorded images by the same investigator. In order to quantify the disease within the pelvic cavity, a practical scoring system was developed in our facility, in which sizes of endometriotic lesions and adhesions were measured by 
Table 1. Backgrounds of the cynomolgus monkeys diagnosed as endometriosis by laparoscopy.

\begin{tabular}{|c|c|c|c|c|c|c|c|c|}
\hline $\begin{array}{l}\text { Animal } \\
\text { number }\end{array}$ & Origin & $\begin{array}{l}\text { Age at the } \\
\text { first laparoscopy } \\
\text { (years) }\end{array}$ & $\begin{array}{l}\text { Body weight at } \\
\text { the first } \\
\text { laparoscopy }(\mathrm{kg})\end{array}$ & $\begin{array}{c}\text { Total } \\
\text { pregnancies }\end{array}$ & $\begin{array}{c}\text { Vaginal } \\
\text { delivery }\end{array}$ & $\begin{array}{c}\text { Caesarean } \\
\text { sections }\end{array}$ & Abortions & $\begin{array}{c}\text { Months since } \\
\text { previous delivery at } \\
\text { diagnosis }\end{array}$ \\
\hline$\# 1$ & Vietnam & 4.5 & 3.04 & 0 & 0 & 0 & 0 & NA \\
\hline$\# 2$ & Vietnam & 5.4 & 3.31 & 0 & 0 & 0 & 0 & NA \\
\hline$\# 3$ & Vietnam & 13.2 & 2.96 & 0 & 0 & 0 & 0 & NA \\
\hline$\# 4$ & $\operatorname{RCALS}^{\mathrm{a}}\left(\mathrm{C} / \mathrm{V}^{\mathrm{b}}\right)$ & 5.2 & 3.11 & 0 & 0 & 0 & 0 & NA \\
\hline$\# 5$ & China & 10.2 & 3.34 & 1 & 0 & 0 & 1 & 59 \\
\hline$\# 6$ & Vietnam & 14.5 & 3.62 & 3 & 0 & 2 & 1 & 2 \\
\hline$\# 7$ & Philippines & 5.6 & 3.14 & 0 & 0 & 0 & 0 & NA \\
\hline$\# 8$ & Vietnam & 8.8 & 3.30 & 0 & 0 & 0 & 0 & NA \\
\hline$\# 9$ & RCALS $\left(\mathrm{V} / \mathrm{V}^{\mathrm{b}}\right)$ & 12.8 & 3.68 & 2 & 0 & 0 & 2 & 5 \\
\hline$\# 10$ & $\operatorname{RCALS}\left(\mathrm{C} / \mathrm{C}^{\mathrm{b}}\right)$ & 5.6 & 3.71 & 0 & 0 & 0 & 0 & NA \\
\hline \#11 & China & 12.9 & 3.15 & 1 & 1 & 0 & 0 & 70 \\
\hline
\end{tabular}

NA, not applicable.

${ }^{a}$ RCALS indicates that the monkeys were born by artificial breeding at Research Center for Animal Life Science at Shiga University of Medical Science.

${ }^{\mathrm{b}} \mathrm{C}$ and $\mathrm{V}$ indicate parents originated from China and Vietnam, respectively.

utilization of routinely used devices, and scored 1-4 (Table 2). Two measure references were used: the head of the operating rod, $3 \mathrm{~mm}$ in diameter, and the distance from the head of the operating rod to the yellow reference line, $5 \mathrm{~mm}$ in length. Score 1 was the criteria with the smallest measurable size $(<3 \mathrm{~mm})$. Score 2 was the criteria with the second smallest measurable size $(\geq 3 \mathrm{~mm}$ and $<6 \mathrm{~mm})$. Score 3 was the criteria that includes larger sizes of endometriotic lesions observable with laparoscopy ( $\geq 6 \mathrm{~mm}$ and $<50 \mathrm{~mm}$ ). Score 4 was the criteria that includes lesions that could be hard to observe ( $\geq 50 \mathrm{~mm})$.

\section{Ethical approval}

This study was carried out in strict accordance with the Guidelines for the Husbandry and Management of Laboratory Animals of the Research Center for Animal Life Science at Shiga University of Medical Science and in strict accordance with Fundamental Guidelines for Proper Conduct of Animal Experiments and Related Activities in Academic Research Institutions under the jurisdiction of

Table 2. Scoring of endometriosis by laparoscopic observation in cynomolgus monkeys.

\begin{tabular}{ccc}
\hline Score & Endometriotic lesion $^{\mathrm{a}}$ & Adhesion $^{\mathrm{b}}$ \\
\hline 1 & $<3 \mathrm{~mm}$ & $<3 \mathrm{~mm}$ \\
2 & $\geq 3 \mathrm{~mm}$ and $<6 \mathrm{~mm}$ & $\geq 3 \mathrm{~mm}$ and $<6 \mathrm{~mm}$ \\
3 & $\geq 6 \mathrm{~mm}$ and $<50 \mathrm{~mm}$ & $\geq 6 \mathrm{~mm}$ and $<50 \mathrm{~mm}$ \\
4 & $\geq 50 \mathrm{~mm}$ & $\geq 50 \mathrm{~mm}$ \\
\hline
\end{tabular}

The sizes of endometriotic lesions and adhesions were independently measured and scored.

${ }^{a}$ Redness, brown to black depositions, vesicles and cysts were regarded as lesions related to endometriosis.

${ }^{\mathrm{b}}$ White fibrous lesions between organs were regarded as adhesions. the Ministry of Education, Culture, Sports, Science and Technology, Japan. The procedures were approved by the Animal Care and Use Committee of Shiga University of Medical Science (Approval number: 2016114). The Research Center for Animal Life Science at Shiga University of Medical Science has a permit for importation of cynomolgus monkeys.

\section{Histology}

Biopsy samples were immersed into $10 \%$ neutralized formalin, dehydrated, and embedded in paraffin. They were cut into 3- $\mu \mathrm{m}$-thick sections, and the sections were stained with hematoxylin and eosin (H \& E) and observed under a light microscope. Immunohistochemistry was performed on serial sections. Sections were incubated overnight at $4^{\circ} \mathrm{C}$ with antibodies specific against CD3 (1:50 dilution, clone: F7.2.38, Agilent Technologies Japan Ltd., Tokyo, Japan), CD163 (1:100 dilution, clone EDHu1, AbD Serotec, Kidlington, UK) and estrogen receptor alpha (1:100 dilution, clone: 1D5, Thermo Fisher Scientific Inc., CA). They were then incubated with horseradish peroxidase-conjugated anti-mouse IgG (Nichirei Biosciences, Tokyo, Japan) for $1 \mathrm{~h}$, followed by incubation with 3,3'-diaminobenzidine (Nichirei Biosciences). The slides were counterstained with hematoxylin. Pictures were taken at $40 \times$ or $400 \times$ magnification (ECLIPSE E600, Nikon Inc., Tokyo, Japan).

\section{Results}

Prevalence, favorite anatomical sites and development of endometriosis in cynomolgus monkeys

In our primary search for spontaneous endometriosis in cynomolgus monkeys, the prevalence was $2.8 \%(5 / 219)$, with higher prevalence in those over 10 years old $(3.77 \%$, $4 / 106)$ than in those between $4-9$ years old $(0.8 \%, 1 / 113)$. Since the higher prevalence in older monkeys suggested 
that lesions spread over age, relatively young monkeys undergoing laparoscopy for breeding were screened for endometriosis and 11 monkeys were used to observe the spatiotemporal development of the disease in the pelvic cavity. The monkeys underwent monthly laparoscopies up to two years. The mean weight and age of the animals at the first laparoscopy in the present study was $3.3 \mathrm{~kg}$ (SD 0.26 ) and 8.9 years old (SD 3.87), respectively (Table 1). None of the monkeys underwent continuous weight loss during the study (Fig. 1). The mean weight at the last laparoscopy was $3.4 \mathrm{~kg}$ (SD 0.49) and change of weight between the first and the last laparoscopy was not significant $(\mathrm{p}=0.33)$. Four monkeys had previous pregnancies (Table 1). The menstrual cycle was regular in monkeys \#2, $\# 3$, \#4, \#6, \#9, \#10 and \#11, and it was irregular in monkeys $\# 1$, \#7 and \#8 (Table 3). Regurgitation of blood into the pelvic cavity (retrograde menstruation) was frequently noted in monkey $\# 9$, and less frequently noted in monkeys \#5 and \#11 (Table 3, Fig. 2A, B).

Laparoscopy was performed every month to evaluate the development of each endometriosis lesion and adhesion in detail. Lesions including redness, brown to black depo-

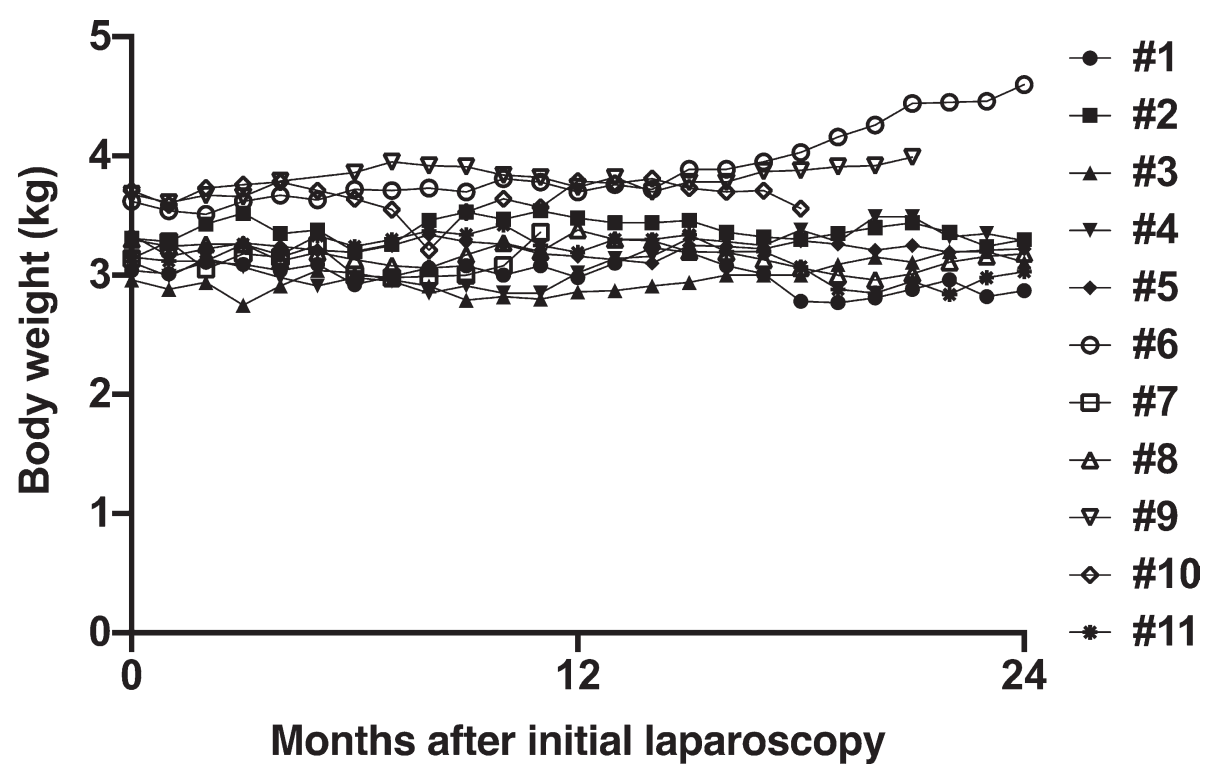

Fig. 1. Body weight of monkeys at each laparoscopic observation.

To ensure that monkeys were not suffering from continuing monthly laparoscopies, body weights were monitored every month. None of the monkeys underwent continuous weight loss during the study. The mean weight at the first and last laparoscopy was $3.3 \mathrm{~kg}$ (SD 0.26) and $3.4 \mathrm{~kg}$ (SD 0.49), respectively, and change of weight between the first and the last laparoscopy was not significant $(\mathrm{p}=0.33)$.

Table 3. Day of menstrual cycle of cynomolgus monkeys at each laparoscopic observation.

\begin{tabular}{|c|c|c|c|c|c|c|c|c|c|c|c|c|c|c|c|c|c|c|c|c|c|c|c|c|c|}
\hline \multicolumn{26}{|c|}{ Months of follow-up after the initial observation } \\
\hline $\begin{array}{l}\text { Animal } \\
\text { number }\end{array}$ & 0 & 1 & 2 & 3 & 4 & 5 & 6 & 7 & 8 & 9 & 10 & 11 & 12 & 13 & 14 & 15 & 16 & 17 & 18 & 19 & 20 & 21 & 22 & 23 & 24 \\
\hline$\# 1$ & 10 & 38 & 66 & 18 & 46 & 18 & 46 & 74 & 24 & 10 & 1 & 36 & 8 & 7 & 35 & 14 & 42 & 77 & 105 & 133 & 168 & 196 & 1 & 36 & 7 \\
\hline$\# 2$ & 26 & 23 & 19 & 25 & 19 & 12 & 17 & 15 & 12 & 25 & 17 & 22 & 21 & 20 & 19 & 25 & 25 & 29 & 27 & 9 & 12 & 12 & 12 & 18 & 21 \\
\hline$\# 3$ & 3 & 27 & 23 & 25 & 19 & 13 & 5 & 33 & 1 & 6 & 5 & 7 & 6 & 4 & 32 & 4 & 32 & 30 & 19 & 17 & 22 & 21 & 21 & 20 & 18 \\
\hline$\# 4$ & 1 & 36 & 64 & 26 & 30 & 2 & 9 & 10 & 31 & 66 & 5 & 33 & 61 & 13 & 5 & 40 & 68 & 96 & 1 & 29 & 18 & 19 & 47 & 6 & 34 \\
\hline$\# 5$ & 377 & 411 & 439 & 468 & 502 & 530 & 558 & 600 & 621 & 656 & 684 & 712 & 740 & 775 & 803 & 838 & 866 & 894 & 929 & 957 & 985 & 1,020 & 1,048 & 1,076 & 1,104 \\
\hline$\# 6$ & 17 & 14 & 8 & 11 & 9 & 7 & 10 & 6 & 5 & 13 & 34 & 29 & 25 & 19 & 14 & 16 & 13 & 17 & 12 & 7 & 9 & 2 & 30 & 4 & 1 \\
\hline$\# 7$ & 24 & 16 & 15 & 13 & 3 & 1 & 21 & 49 & 77 & 119 & 140 & 3 & & & & & & & & & & & & & \\
\hline$\# 8$ & 257 & 13 & 41 & 76 & 104 & 133 & 167 & 195 & 223 & 258 & 7 & 6 & 34 & 62 & 90 & 125 & 153 & 188 & 216 & 244 & 279 & 307 & 335 & 370 & 398 \\
\hline$\# 9$ & 1 & 1 & 36 & 23 & 29 & 2 & 1 & 29 & 7 & 7 & 42 & 1 & 2 & 5 & 6 & 5 & 14 & 10 & 10 & 10 & 8 & 16 & & & \\
\hline$\# 10$ & 30 & 16 & 18 & 17 & 14 & 13 & 47 & 6 & 34 & 27 & 55 & 12 & 40 & 26 & 1 & 36 & 11 & 15 & 43 & & & & & & \\
\hline$\# 11$ & 39 & 1 & 28 & 4 & 4 & 33 & 67 & 6 & 4 & 39 & 67 & 17 & 15 & 13 & 13 & 48 & 22 & 57 & 27 & 21 & 56 & 26 & 54 & 1 & 29 \\
\hline
\end{tabular}

Eleven female cynomolgus monkeys were followed up by monthly laparoscopy for maximum 24 months. Menstruation was assessed by external bleeding. The numbers indicate the days after onset of the most recent menstruation at each laparoscopy. Shadow indicates that retrograde menstruation was noted by laparoscopic observation. 

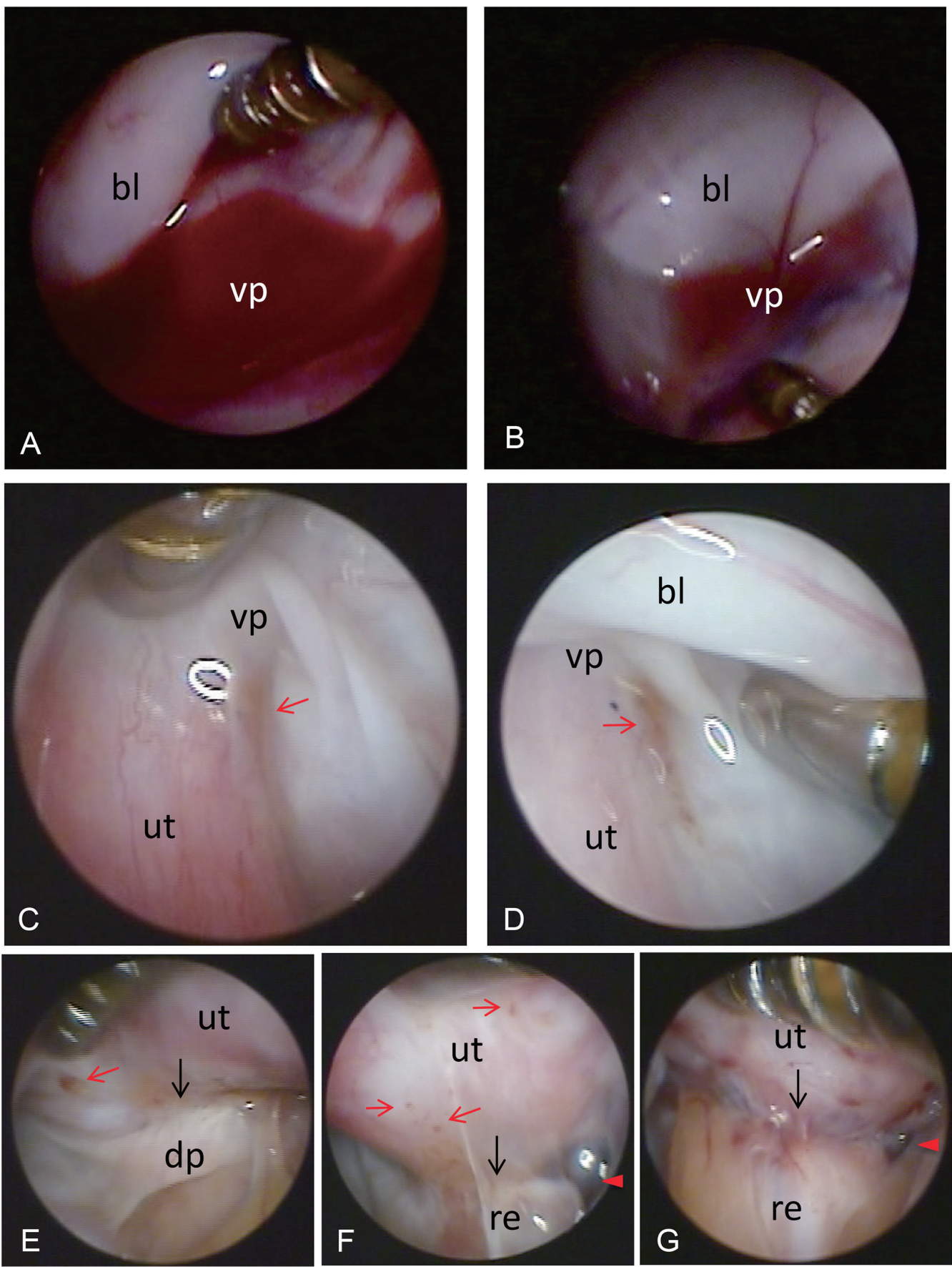

Fig. 2. Retrograde menstruation, endometriotic lesions and adhesions based on laparoscopic observation in cynomolgus monkeys.

Stationary pictures were taken from recorded images of the pelvic cavity. Retrograde menstruation of monkey \#9 (A) and \#5 (B), endometriotic lesions of monkey \#7 (C and D) and \#9 (E-G) are shown. (A) Retrograde menstruation in the left vesicouterine pouch of monkey \#9 at 13 months after the initial laparoscopy. (B) Retrograde menstruation in the right vesicouterine pouch of monkey \#5 at 2 months after the initial laparoscopy. (C) An endometriotic lesion at the initial laparoscopy scored 1: a brown deposition of smaller than $3 \mathrm{~mm}$ in largest diameter (red arrow). (D) An endometriotic lesion one month after the initial laparoscopy scored 2: a brown deposition of larger than $3 \mathrm{~mm}$ but smaller than 6 $\mathrm{mm}$ in largest diameter (red arrow). (E) An endometriotic lesion 6 months before the initial laparoscopy scored 1: a brown deposition smaller than $3 \mathrm{~mm}$ in largest diameter (red arrow) and an adhesion scored 2: adhesion larger than 3 $\mathrm{mm}$ but smaller than $6 \mathrm{~mm}$ (black arrow). (F) An endometriotic lesion 3 months after the initial laparoscopy scored 3: a cyst larger than $6 \mathrm{~mm}$ but smaller than $50 \mathrm{~mm}$ (red arrowhead) with brown depositions smaller than $3 \mathrm{~mm}$ in largest diameter (red arrows) and an adhesion scored 3: adhesion larger than $6 \mathrm{~mm}$ but smaller than $50 \mathrm{~mm}$ (black arrow). (G) An endometriotic lesion 7 months after the initial laparoscopy scored 3: a cyst larger than $6 \mathrm{~mm}$ but smaller than $50 \mathrm{~mm}$ (red arrowhead) and an adhesion scored 4: adhesion larger than $50 \mathrm{~mm}$ in largest diameter (black arrow).

B1, bladder; vp, vesicouterine pouch; ut, uterus; dp, Douglas' pouch; re, rectum. 
sitions, vesicles and cysts in the peritoneal cavity were regarded as lesions related to endometriosis (Fig. 2C-G, red arrows and arrowheads). White fibrous lesions between organs were regarded as adhesions (Fig. 2E-G, black arrows). In Fig. 2C, a brown deposition was smaller than 3 $\mathrm{mm}$ in diameter in the vesicouterine pouch (red arrow) that was scored 1 (monkey \#7 at the initial laparoscopy). The brown deposition spread to more than $3 \mathrm{~mm}$ but less than 6 $\mathrm{mm}$ in diameter at the second follow-up laparoscopy, and the endometriotic lesion was thus scored 2 (Fig. 2D). Endometriotic lesions and adhesions in Douglas' pouch (Fig. 2E-G) were observed six months before the initiation of monthly laparoscopies, and 3 and 7 months after the initial laparoscopy, respectively, in monkey \#9. The total scores of endometriotic lesions and adhesions showed that endometriosis developed in all 11 monkeys during 11 to 24 months of follow, and the rate of progression varied greatly between individuals (Fig. 3, Tables 4, 5).

The spatiotemporal development of endometriosis in the pelvic cavity was evaluated by mapping each endometriotic lesion and adhesion at the initial laparoscopy, 11 to 12 months after the initial laparoscopy, and 18 to 24 months after the initial laparoscopy. At the initial laparoscopy, endometriotic lesions were exclusively found in the vesicouterine pouch in $45.4 \%$ of the monkeys $(5 / 11, \# 2,3,4,7$ and 11), whereas they were exclusively found in the Douglas' pouch in $9.09 \%(1 / 11$, \#6) (Fig. 4, Table 6). Endometriotic lesions were found in both the vesicouterine and Douglas' pouch in $45.4 \%(5 / 11, \# 1,5,8,9$ and 10$)$. No lesions were found in the ovaries nor adnexa. Endometriotic lesions were still exclusively found in the vesicouterine pouch at 12 and 24 months in monkey \#2, whereas they spread to the Douglas' pouch/uterus/adnexa in the other monkeys (Fig. 4, Tables 7, 8). Thus, endometri- otic lesions favored the vesicouterine pouch at the early stage and spread to the Douglas' pouch over time.

Adhesions were found exclusively in the Douglas' pouch in $9.09 \%(1 / 11, \# 9)$ and both in the Douglas' pouch and ovaries/adnexa in $18.1 \%(2 / 11, \# 8$ and 11$)$ at the initial laparoscopy. No adhesions were found in $72.7 \%(8 / 11$, \#1-7 and 10) (Fig. 4, Table 6). Eleven to 12 months after the initial laparoscopy, adhesions were found exclusively in the Douglas' pouch in $45.4 \%(5 / 11, \# 3-7)$ and in the Douglas' pouch and vesicouterine pouch/uterus/ovaries/ adnexa/omentum in $36.3 \%(4 / 11$, \#8-11). No adhesions were found in $18.1 \%(2 / 11, \# 1$ and 2$)$ (Fig. 4, Table 7). Eighteen to 24 months after the initial laparoscopy, adhesions were found exclusively in the Douglas' pouch in $30 \%$ (3/10, \#4-6) and in the Douglas' pouch and vesicouterine pouch/uterus/ovaries/adnexa/omentum in 70\% (7/10, \#1-3, 8-11) (Fig. 4, Table 8). In summary, adhesions were mainly found in the Douglas' pouch.

De novo lesions appeared in two patterns; firstly, as a small redness or brown deposition adjacent to the initial lesion that were found in all monkeys (Fig. 2F); secondly, in different locations from the initial lesion (e.g., from the vesicouterine to the Douglas' pouch, or from the left to the right side of the vesicouterine pouch) in $63.6 \%$ of the monkeys (7/11, \#1-7) (Fig. 4). In monkey \#10, a cyst beneath the peritoneum expanded continuously from the vesicouterine to the Douglas' pouch (Fig. 4). Some of the small rednesses or brown depositions disappeared in $18.2 \%$ of the monkeys (2/11, \#3 and 4) (Fig. 4).

\section{Histology of laparoscopicaly diagnosed endometriosis in cynomolgus monkeys}

Endometriosis was confirmed by histology in one monkey with an advanced lesion (\#11) and another monkey

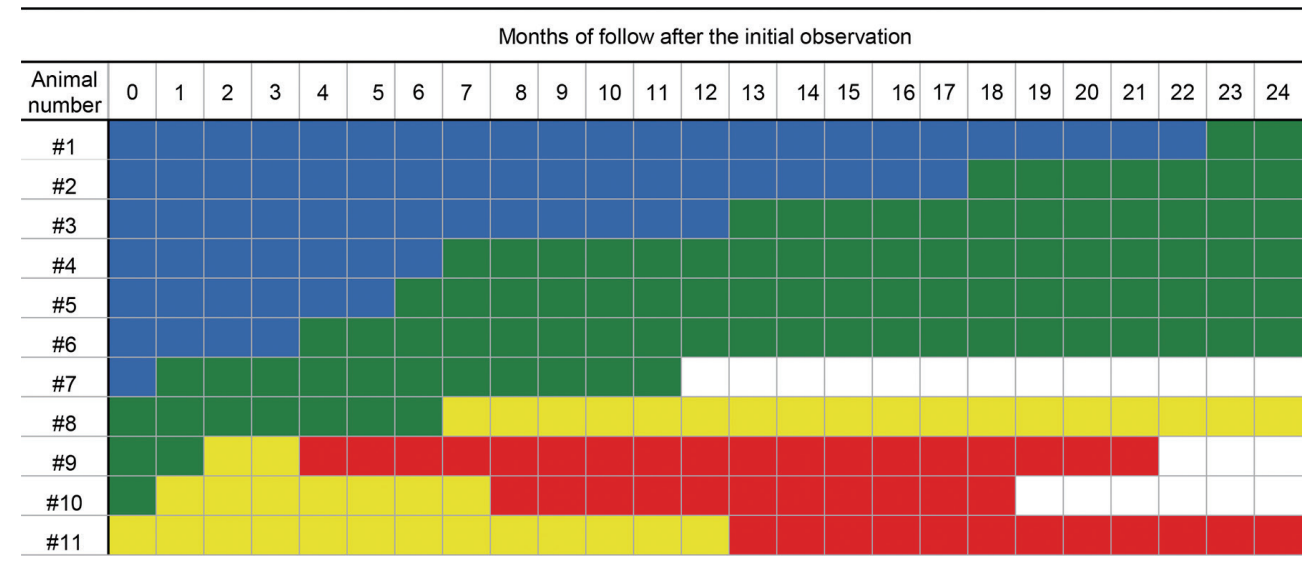

Fig. 3. Progression of endometriosis assessed by scoring of endometriotic lesions and adhesions in cynomolgus monkeys. Laparoscopy was performed every month, and endometriotic lesions and adhesions were scored based on sizes (Table 2). The scores were summed up and visualized by showing the total scores in colors: blue (scores 1 and 2), green (scores 3 and 4), yellow (scores 5 and 6) and red (scores 7 and 8). In monkey \#7, the last laparoscopy was performed 11 months after the initial laparoscopy since it died of acute gastrectasia unrelated to endometriosis. In monkey \#9, the last laparoscopy was performed 21 months after the initial laparoscopy since it was used for another experiment. For monkey $\# 10$, the last laparoscopy was performed 18 months after the initial laparoscopy since laparoscopy could not be performed due to fibrosis progression. 
Table 4. Endometriotic lesions diagnosed by laparoscopy in cynomolgus monkeys.

\begin{tabular}{|c|c|c|c|c|c|c|c|c|c|c|c|c|c|c|c|c|c|c|c|c|c|c|c|c|c|}
\hline \multicolumn{26}{|c|}{ Months of follow-up after the initial observation } \\
\hline $\begin{array}{l}\text { Animal } \\
\text { number }\end{array}$ & 0 & 1 & 2 & 3 & 4 & 5 & 6 & 7 & 8 & 9 & 10 & 11 & 12 & 13 & 14 & 15 & 16 & 17 & 18 & 19 & 20 & 21 & 22 & 23 & 24 \\
\hline$\# 1$ & 1 & 1 & 1 & 1 & 1 & 1 & 1 & 1 & 1 & 1 & 1 & 1 & 1 & 1 & 1 & 1 & 1 & 1 & 1 & 1 & 1 & 1 & 1 & 2 & 2 \\
\hline$\# 2$ & 1 & 1 & 1 & 1 & 1 & 1 & 1 & 1 & 1 & 1 & 1 & 1 & 1 & 1 & 1 & 1 & 1 & 1 & 2 & 2 & 2 & 2 & 2 & 2 & 2 \\
\hline$\# 3$ & 1 & 1 & 1 & 1 & 1 & 1 & 1 & 1 & 1 & 1 & 1 & 1 & 1 & 2 & 2 & 2 & 2 & 2 & 2 & 2 & 2 & 2 & 2 & 2 & 2 \\
\hline$\# 4$ & 1 & 1 & 1 & 1 & 1 & 1 & 1 & 1 & 1 & 1 & 2 & 2 & 2 & 2 & 2 & 2 & 2 & 2 & 2 & 2 & 2 & 2 & 2 & 2 & 2 \\
\hline$\# 5$ & 1 & 1 & 1 & 1 & 1 & 1 & 2 & 2 & 2 & 2 & 2 & 2 & 2 & 2 & 2 & 2 & 2 & 2 & 2 & 2 & 2 & 2 & 2 & 2 & 2 \\
\hline$\# 6$ & 1 & 2 & 2 & 2 & 2 & 2 & 2 & 2 & 2 & 2 & 2 & 2 & 2 & 2 & 2 & 2 & 2 & 2 & 2 & 2 & 2 & 2 & 2 & 2 & 2 \\
\hline$\# 7$ & 1 & 2 & 2 & 2 & 2 & 2 & 2 & 2 & 2 & 2 & 2 & 2 & & & & & & & & & & & & & \\
\hline$\# 8$ & 2 & 2 & 2 & 2 & 2 & 2 & 2 & 3 & 3 & 3 & 3 & 3 & 3 & 3 & 3 & 3 & 3 & 3 & 3 & 3 & 3 & 3 & 3 & 3 & 3 \\
\hline$\# 9$ & 2 & 2 & 3 & 3 & 3 & 4 & 4 & 4 & 4 & 4 & 4 & 4 & 4 & 4 & 4 & 4 & 4 & 4 & 4 & 4 & 4 & 4 & & & \\
\hline$\# 10$ & 3 & 3 & 3 & 3 & 3 & 3 & 3 & 3 & 4 & 4 & 4 & 4 & 4 & 4 & 4 & 4 & 4 & 4 & 4 & & & & & & \\
\hline$\# 11$ & 3 & 3 & 3 & 3 & 3 & 3 & 3 & 3 & 3 & 3 & 3 & 3 & 3 & 3 & 3 & 3 & 3 & 3 & 3 & 3 & 3 & 3 & 4 & 4 & 4 \\
\hline
\end{tabular}

Eleven female cynomolgus monkeys were followed up by monthly laparoscopy for maximum 24 months. Endometriotic lesions (redness, brown to black depositions, vesicles and cysts) were measured and scored 1 to 4 according to Table 2 .

Table 5. Adhesions diagnosed by laparoscopy in cynomolgus monkeys.

\begin{tabular}{|c|c|c|c|c|c|c|c|c|c|c|c|c|c|c|c|c|c|c|c|c|c|c|c|c|c|}
\hline \multicolumn{26}{|c|}{ Months of follow-up after the initial observation } \\
\hline $\begin{array}{l}\text { Animal } \\
\text { number }\end{array}$ & 0 & 1 & 2 & 3 & 4 & 5 & 6 & 7 & 8 & 9 & 10 & 11 & 12 & 13 & 14 & 15 & 16 & 17 & 18 & 19 & 20 & 21 & 22 & 23 & 24 \\
\hline$\# 1$ & 0 & 0 & 0 & 0 & 0 & 0 & 0 & 1 & 1 & 1 & 1 & 1 & 1 & 1 & 1 & 1 & 1 & 1 & 1 & 1 & 1 & 1 & 1 & 1 & 1 \\
\hline$\# 2$ & 0 & 0 & 0 & 0 & 0 & 0 & 0 & 0 & 0 & 0 & 0 & 0 & 0 & 0 & 0 & 1 & 1 & 1 & 1 & 1 & 1 & 1 & 1 & 1 & 1 \\
\hline$\# 3$ & 0 & 0 & 0 & 0 & 0 & 0 & 0 & 1 & 1 & 1 & 1 & 1 & 1 & 1 & 2 & 2 & 2 & 2 & 2 & 2 & 2 & 2 & 2 & 2 & 2 \\
\hline$\# 4$ & 0 & 0 & 0 & 0 & 1 & 1 & 1 & 2 & 2 & 2 & 2 & 2 & 2 & 2 & 2 & 2 & 2 & 2 & 2 & 2 & 2 & 2 & 2 & 2 & 2 \\
\hline$\# 5$ & 0 & 1 & 1 & 1 & 1 & 1 & 1 & 1 & 1 & 1 & 1 & 1 & 1 & 1 & 1 & 1 & 2 & 2 & 2 & 2 & 2 & 2 & 2 & 2 & 2 \\
\hline$\# 6$ & 0 & 0 & 0 & 0 & 1 & 1 & 1 & 1 & 2 & 2 & 2 & 2 & 2 & 2 & 2 & 2 & 2 & 2 & 2 & 2 & 2 & 2 & 2 & 2 & 2 \\
\hline$\# 7$ & 0 & 2 & 2 & 2 & 2 & 2 & 2 & 2 & 2 & 2 & 2 & 2 & & & & & & & & & & & & & \\
\hline$\# 8$ & 2 & 2 & 2 & 2 & 2 & 2 & 2 & 2 & 2 & 3 & 3 & 3 & 3 & 3 & 3 & 3 & 3 & 3 & 3 & 3 & 3 & 3 & 3 & 3 & 3 \\
\hline$\# 9$ & 2 & 2 & 2 & 3 & 4 & 4 & 4 & 4 & 4 & 4 & 4 & 4 & 4 & 4 & 4 & 4 & 4 & 4 & 4 & 4 & 4 & 4 & & & \\
\hline$\# 10$ & 0 & 2 & 2 & 2 & 3 & 3 & 3 & 3 & 3 & 4 & 4 & 4 & 4 & 4 & 4 & 4 & 4 & 4 & 4 & & & & & & \\
\hline$\# 11$ & 3 & 3 & 3 & 3 & 3 & 3 & 3 & 3 & 3 & 3 & 3 & 3 & 3 & 4 & 4 & 4 & 4 & 4 & 4 & 4 & 4 & 4 & 4 & 4 & 4 \\
\hline
\end{tabular}

Eleven female cynomolgus monkeys were followed up by monthly laparoscopy for maximum 24 months. Adhesions (white fibrous lesions between organs) were measured and scored 1 to 4 according to Table 2 .

with an early lesion (\#7). In monkey \#11, one month before the initiation of monthly laparoscopies, two biopsy specimens were collected; from a cyst (Fig. 5A) and a vesicle (Fig. 5D). The cyst wall was composed of endometrial epithelial cells, stromal cells and hemosiderin-laden macrophages (Fig. 5B, C). In the latter lesion, endometrial glands were accompanied by endometrial stromal cells with fibrosis and mild infiltration of lymphocytes in the serosa (Fig. $5 \mathrm{E}, \mathrm{F})$.

Since monkey \#7 died of acute gastrectasia unrelated to endometriosis two days after the follow-up laparoscopy performed 11 months after the initial laparoscopy, tissue was collected from a brown deposition on the peritoneum of the vesicouterine pouch (the lesion observed by laparoscopy is shown in Fig. 2D). Infiltration of mononuclear cells (Fig. 5G, H) and a gland-like epithelium (Fig. 5G, I) were seen in the peritoneum of the tissue. Disappearance of some of the small endometriotic lesions in $18.2 \%(2 / 11)$ of monkeys raised the possibility of early lesions being rejected by the host immune response. Since macrophages and $\mathrm{T}$ lymphocytes are involved in the pathology of endometriosis (Khan et al. 2004; Hanada et al. 2018), CD3, a T cell receptor that is required for the activation of $\mathrm{T}$ cells, and CD163, a high affinity scavenger receptor for the hemogloblin-haptoglobulin complex, known as a specific marker for macrophages, were stained. Mononuclear cells consisted of CD3-positive lymphocytes (T cells) (Fig. 5J) and CD163-positive macrophages (Fig. 5K). Macrophage derived-foreign body multinucleated giant cells, CD163 weakly positive (arrow), were found, suggesting that ectopic endometrium was recognized as foreign bodies. The epithelium in the endometriotic lesion expressed estrogen 


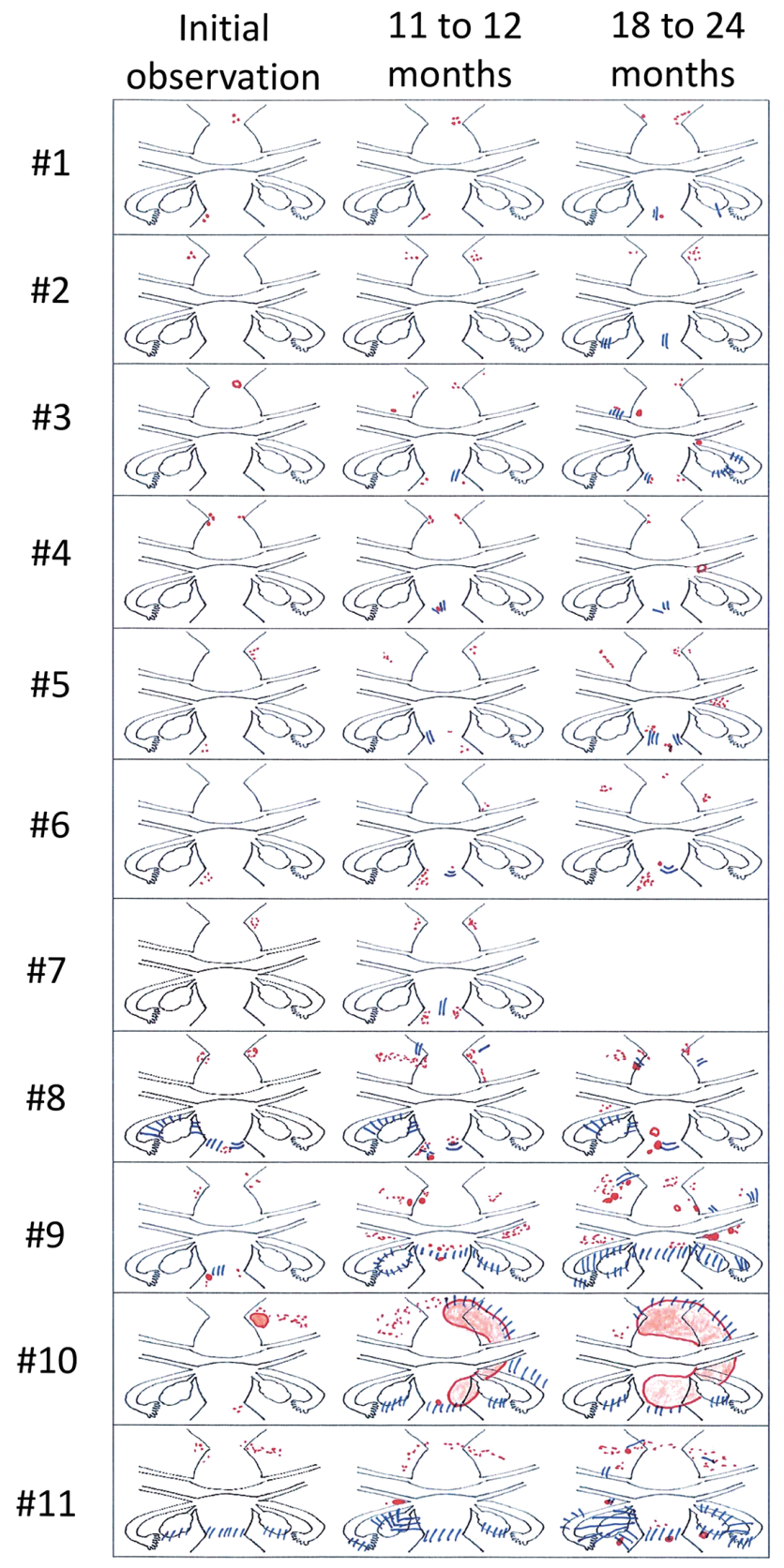

Fig. 4. Spatiotemporal mapping of endometriotic lesions and adhesions in cynomolgus monkeys for up to two years. The course of endometriosis was assessed by performing monthly follow-up laparoscopies. Endometriotic lesions and adhesions were mapped at the initial observation, 11 to 12 months and 18 to 24 months after the initial observation. The upper part of the illustration shows the vesicouterine pouch and the lower part shows the Douglas's pouch of each monkey. Endometriotic lesions: red; adhesions: blue lines between two anatomical locations. In monkey \#7, the last laparoscopy was performed 11 months after the initial laparoscopy since it died of acute gastrectasia unrelated to endometriosis. In monkey \#9, the last laparoscopy was performed 21 months after the initial laparoscopy since it was used for another experiment. For monkey \#10, the last laparoscopy was performed 18 months after the initial laparoscopy since laparoscopy could not be performed due to fibrosis progression. receptors in the nucleus, indicating an endometrial gland (Fig. 5L). Altogether, laparoscopically diagnosed endometriosis was histologically confirmed in monkeys with a relatively advanced lesion and an early lesion, and the involvement of host immune responses was suggested to account for the disappearance of small endometriotic lesions.

\section{Discussion}

In the present study, we revealed the natural history of spontaneously occurred endometriosis in cynomolgus monkeys by performing monthly laparoscopies up to two years, mapping endometriotic lesions and adhesions in detail. We found that endometriosis is a progressive disease with variable speeds of progression among individuals as reported in humans (Koninckx et al. 1991; Bulun 2009).

At the initial observation, endometriotic lesions were observed more frequently in the vesicouterine pouch than in the Douglas' pouch, whereas in humans, favorite anatomical sites of endometriosis are the ovaries and Douglas' pouch (Hoshiai et al. 1993; Gylfason et al. 2010; Yamanaka et al. 2012). Of note, even after 2 years of observation, an endometriotic cyst of the ovary (endometrioma) was not observed, in accordance with a report from baboons (D'Hooghe et al. 1991). This is in line with a previous report in cynomolgus monkeys with endometriosis where lesions and adhesions were frequently found at the vesicouterine pouch by laparoscopy $(44.4 \%$; 4/9) (NishimotoKakiuchi et al. 2018). Moreover, a study of laparoscopy in baboons with initial endometriosis $(n=11)$ reports the findings after 10 months, where they found 67 lesions that consisted mainly of new implants located on the uterine peritoneum (58\%) and the uterovesical fold (18\%) (D'Hooghe et al. 1992). The high occurrence of endometriosis in the vesicouterine pouch in nonhuman primates might be explained by the posture; unlike humans, since monkeys do not lay down in a supine position, the fimbria of fallopian tubes face the vesicouterine pouch when monkeys sleep or rest in a sitting position. In addition, since cynomolgus monkeys have a very low amount of ascites (usually uncollectable), their ovaries do not contact ascites that potentially contains fragments of regurgitated endometrium. These differences between monkeys and humans might explain the different favorite anatomical sites of spontaneous endometriosis.

There have been two leading theories regarding the origin of endometriosis, which are coelomic metaplasia (Gruenwald 1942) and retrograde menstruation (Sampson 1927). The high occurrence of endometriosis in the vesicouterine pouch in the present study and other studies in cynomolgus monkeys and baboons (D'Hooghe et al. 1991, 1992; Nishimoto-Kakiuchi et al. 2018) strongly support the latter hypothesis that menstrual regurgitation causes dissemination and implantation of endometriotic tissues in the pelvic cavity. However, contrary to studies that report the vesicouterine pouch as a frequent site of endometriosis in nonhuman primates, there is a report in cynomolgus monkeys retired from breeding in which endometriosis mainly 
Table 6. Sites of endometriotic lesion and adhesion at the initial laparoscopy.

\begin{tabular}{|c|c|c|}
\hline $\begin{array}{l}\text { Animal } \\
\text { number }\end{array}$ & Sites of endometriotic lesion & Sites of adhesion \\
\hline$\# 1$ & vesicouterine pouch $(\mathrm{R})$, Douglas' pouch $(\mathrm{L})$ & \\
\hline$\# 2$ & vesicouterine pouch $(\mathrm{L})$ & \\
\hline$\# 3$ & vesicouterine pouch $(\mathrm{R})$ & \\
\hline$\# 4$ & vesicouterine pouch $(\mathrm{R}, \mathrm{L})$ & \\
\hline$\# 5$ & vesicouterine pouch (R), Douglas' pouch (L) & \\
\hline \#6 & Douglas' pouch (L) & \\
\hline$\# 7$ & vesicouterine pouch $(\mathrm{R})$ & \\
\hline$\# 8$ & vesicouterine pouch (R, L), Douglas' pouch (L) & Douglas' pouch (L), uterus-left ovary-left salpinx \\
\hline$\# 9$ & vesicouterine pouch $(\mathrm{R}, \mathrm{L})$, Douglas' pouch $(\mathrm{R}, \mathrm{L})$ & Douglas' pouch (L) \\
\hline$\# 10$ & vesicouterine pouch (R), Douglas' pouch $(\mathrm{R})$ & \\
\hline$\# 11$ & vesicouterine pouch (W) & Douglas' pouch $(\mathrm{C})$, both ovaries-omentum majus \\
\hline
\end{tabular}

Eleven monkeys underwent laparoscopy for evaluation of endometriotic lesions and adhesions.

$\mathrm{R}$, right; L, left; C, center; W, whole.

Table 7. Sites of endometriotic lesion and adhesion 11 to 12 months after the initial laparoscopy.

\begin{tabular}{|c|c|c|}
\hline $\begin{array}{l}\text { Animal } \\
\text { number }\end{array}$ & Sites of endometriotic lesion & Sites of adhesion \\
\hline$\# 1$ & vesicouterine pouch $(\mathrm{R})$, Douglas' pouch $(\mathrm{L})$ & \\
\hline$\# 2$ & vesicouterine pouch $(\mathrm{R}, \mathrm{L})$ & \\
\hline$\# 3$ & vesicouterine pouch $(\mathrm{R}, \mathrm{L})$, Douglas' pouch $(\mathrm{R}, \mathrm{L})$ & Douglas' pouch $(\mathrm{R})$ \\
\hline$\# 4$ & vesicouterine pouch $(\mathrm{R}, \mathrm{L})$, Douglas' pouch $(\mathrm{C})$ & Douglas' pouch $(\mathrm{C})$ \\
\hline$\# 5$ & vesicouterine pouch $(\mathrm{R}, \mathrm{L})$, Douglas' pouch $(\mathrm{R})$, uterus & Douglas' pouch (L) \\
\hline$\# 6$ & vesicouterine pouch $(\mathrm{R})$, Douglas' pouch $(\mathrm{L}, \mathrm{C})$ & Douglas' pouch (C) \\
\hline$\# 7^{\mathrm{a}}$ & vesicouterine pouch $(R, L)$, Douglas' pouch $(R, L)$ & Douglas' pouch $(\mathrm{C})$ \\
\hline$\# 8$ & vesicouterine pouch (R, L), Douglas' pouch (W) & $\begin{array}{l}\text { vesicouterine pouch }(\mathrm{R}, \mathrm{L}) \text {, Douglas' pouch }(\mathrm{R}) \text {, uterus-left } \\
\text { ovary-left salpinx }\end{array}$ \\
\hline$\# 9$ & $\begin{array}{l}\text { vesicouterine pouch }(\mathrm{R}, \mathrm{L}) \text {, Douglas' pouch }(\mathrm{W}) \text {, } \\
\text { round ligament }(\mathrm{R}, \mathrm{L})\end{array}$ & Douglas' pouch (W), around both ovaries \\
\hline$\# 10$ & $\begin{array}{l}\text { vesicouterine pouch }(\mathrm{W}) \text {, Douglas' pouch }(\mathrm{R}, \mathrm{C}) \text {, } \\
\text { round ligament }(\mathrm{R})\end{array}$ & $\begin{array}{l}\text { vesicouterine pouch (R), omentum majus - left ovary, } \\
\text { omentum majus-right ovary, Douglas' pouch (C-R) }\end{array}$ \\
\hline$\# 11$ & vesicouterine pouch $(\mathrm{W})$, round ligament $(\mathrm{L})$ & $\begin{array}{l}\text { Douglas' pouch (W), omentum majus-left salpinx-left } \\
\text { ovary-uterus, omentum majus-right ovary }\end{array}$ \\
\hline
\end{tabular}

Eleven monkeys underwent laparoscopy for evaluation of endometriotic lesions and adhesions.

$\mathrm{R}$, right; L, left; C, center; W, whole.

${ }^{a}$ Laparoscopy was performed 11 months after the initial laparoscopy.

involved the ovaries with formation of cysts (14/27) (Ami et al. 1993). This may be attributed to the older age of the monkeys with endometriosis compared to that in the present study ( 15.3 vs. 8.9 years old). Another possibility to explain endometriotic cysts of the ovary is a mechanism different from retrograde menstruation. It has been proposed that peritoneal endometriosis and ovarian endometriosis belong to distinct entities (Nisolle and Donnez 1997), and this proposal is supported by clonality studies where pelvic endometriotic lesions were polyclonal, whereas ovarian endometriotic lesions were monoclonal (Jimbo et al. 1997; Nabeshima et al. 2003). Indeed, in the report from Nishimoto-Kakiuchi et al. (2018), one monkey out of the 9 laparoscopically-diagnosed monkeys had a lesion in the ovary and not in any other locations, which contradicts with retrograde menstruation as the origin. If larger numbers of monkeys were studied, endometriotic cysts of the ovary may be found in our institute as well. However, the present study suggests that the main origin of endometriosis is retrograde menstruation in which early lesions start from the vesicouterine pouch in nonhuman primates and spread to the Douglas' pouch or ovaries/adnexa over time.

We found that the rate of progression varied greatly among individuals. This is the most essential and important point when using nonhuman primates since they are genetically heterogenous as humans. The fastest progression was seen in monkey \#9 (Figs. 3, 4) that coincides with frequent regurgitation of menstruation into the pelvic cavity (shown 
Table 8. Sites of endometriotic lesion and adhesion 18 to 24 months after the initial laparoscopy.

\begin{tabular}{|c|c|c|}
\hline $\begin{array}{l}\text { Animal } \\
\text { number }\end{array}$ & Sites of endometriotic lesion & Sites of adhesion \\
\hline$\# 1$ & vesicouterine pouch $(\mathrm{R}, \mathrm{L})$, Douglas' pouch $(\mathrm{R})$ & right ovary, Douglas' pouch (C) \\
\hline$\# 2$ & vesicouterine pouch $(\mathrm{R}, \mathrm{L})$ & left ovary, Douglas' pouch (C) \\
\hline$\# 3$ & $\begin{array}{l}\text { vesicouterine pouch }(\mathrm{R}, \mathrm{L}) \text {, Douglas' pouch }(\mathrm{R}, \mathrm{L}) \text {, } \\
\text { oviduct }(\mathrm{R})\end{array}$ & $\begin{array}{l}\text { vesicouterine pouch }(\mathrm{L}) \text {, Douglas' pouch }(\mathrm{L}) \text {, } \\
\text { right ovary-right salpinx }\end{array}$ \\
\hline$\# 4$ & vesicouterine pouch $(\mathrm{L})$, round ligament $(\mathrm{R})$ & Douglas' pouch $(\mathrm{C})$ \\
\hline$\# 5$ & $\begin{array}{l}\text { vesicouterine pouch }(\mathrm{R}, \mathrm{L}) \text {, Douglas' pouch }(\mathrm{C}) \text {, } \\
\text { round ligament }(\mathrm{R}) \text {, uterus }\end{array}$ & Douglas' pouch $(\mathrm{R}, \mathrm{L})$ \\
\hline$\# 6$ & vesicouterine pouch $(\mathrm{R}, \mathrm{L}, \mathrm{C})$, Douglas' pouch $(\mathrm{L}, \mathrm{C})$ & Douglas' pouch $(\mathrm{C})$ \\
\hline$\# 8$ & vesicouterine pouch $(\mathrm{R}, \mathrm{L})$, Douglas' pouch $(\mathrm{L})$, uterus & $\begin{array}{l}\text { vesicouterine pouch }(\mathrm{R}, \mathrm{L}) \text {, Douglas' pouch }(\mathrm{C}) \text {, } \\
\text { uterus-left ovary-left salpinx }\end{array}$ \\
\hline$\# 9^{\mathrm{a}}$ & vesicouterine pouch $(\mathrm{W})$, round ligament $(\mathrm{R}, \mathrm{L})$, uterus & $\begin{array}{l}\text { vesicouterine pouch }(\mathrm{R}, \mathrm{L}) \text {, Douglas' pouch }(\mathrm{W}) \text {, } \\
\text { round ligament }(\mathrm{R}) \text {, omentum majus-left salpinx-left ovary, } \\
\text { omentum majus-right salpinx-right ovary }\end{array}$ \\
\hline$\# 10^{\mathrm{b}}$ & $\begin{array}{l}\text { vesicouterine pouch }(\mathrm{W}) \text {, Douglas' pouch }(\mathrm{W}) \text {, } \\
\text { round ligament }(\mathrm{R})\end{array}$ & $\begin{array}{l}\text { vesicouterine pouch (W), omentum majus- left ovary, } \\
\text { omentum majus -right ovary, Douglas' pouch (W) }\end{array}$ \\
\hline$\# 11$ & $\begin{array}{l}\text { vesicouterine pouch }(W) \text {, Douglas' pouch }(\mathrm{R}) \text {, } \\
\text { round ligament }(\mathrm{L}) \text {, uterus, omentum majus }\end{array}$ & $\begin{array}{l}\text { vesicouterine pouch }(\mathrm{R}, \mathrm{L}) \text {, Douglas' pouch }(\mathrm{W}) \text {, } \\
\text { round ligament }(\mathrm{L}) \text {, omentum majus-left salpinx-left } \\
\text { ovary-uterus, omentum majus-right salpinx-right ovary }\end{array}$ \\
\hline
\end{tabular}

Eleven monkeys underwent laparoscopy for evaluation of endometriotic lesions and adhesions.

$\mathrm{R}$, right; L, left; C, center; W, whole.

${ }^{\text {a }}$ Laparoscopy was performed 21 months after the initial laparoscopy.

${ }^{b}$ Laparoscopy was performed 18 months after the initial laparoscopy.

by shadows in Table 3, and Fig. 2A), thus strongly supporting retrograde menstruation as the origin of endometriosis. Furthermore, we found that in monkey \#1, endometriotic lesions were stable for 22 months (Fig. 3, Table 4), and progression at 23 months after the initial laparoscopy coincides with the start of menstruation after a non-menstruation period for 6 months; the onset of menstruation may have accounted for progression, although retrograde menstruation was not observed by laparoscopy. Last but not least, monkeys used in the present study were of different origins, thus they are expected to be genetically different to some extent, leading to variable immune responses that affects the progression of the disease.

Clinical manifestations were not useful to predict the rate of progression; severe loss of appetite accompanied menstruation only in monkey \#6, and loose feces, constipation and mild to severe loss of appetite were sporadically observed in monkeys \#3, 4, and 7-11, with no increase of severity during the observation period. The poor correlation with clinical manifestations and the rate of progression suggests the difficulties in predicting the rate of progression based solely on clinical signs.

We have reported the histopathological observation of a small brown deposition (less than $6 \mathrm{~mm}$ ) on the peritoneum, which is rarely biopsied in humans. Immunohistochemistry revealed CD3-positive $\mathrm{T}$ cells and CD163-positive macrophages, which are both engaged in the pathology of endometriosis (Khan et al. 2004; Hanada et al. 2018). CD163 is the high affinity scavenger receptor for the hemogloblin-haptoglobulin complex, and the activation of CD163-positive macrophages result in the shedding of CD163 from the cell surface (Møller 2012). The appearance of foreign body multinucleated giant cells indicated that the ectopic endometrium was recognized as a foreign body by the host immune system, and the low expression of CD163 on foreign body multinucleated giant cells further suggested the activation of macrophages. It is recently reported that the soluble form of CD163 results in suppression of the adaptive immune responses (O'Connell et al. 2017). Therefore, activated macrophages may alter the local inflammatory milieu, facilitating the ectopic endometrium to escape from host immune responses. The role of CD163 in the pathology of the onset and progression of endometriosis has yet to be elucidated. Considering the histopathological findings and the fact that some small endometriotic lesions disappeared, we think that intervention in host immune responses in the pelvic cavity have the potential to more effectively reject the implantation of ectopic endometrium.

There are two limitations of our study. Firstly, our scoring system was not directly compared to the human classification system of the revised American Society of Reproductive Medicine (r-ASRM). Although r-ASRM classification was used to monitor the disease in cynomolgus monkeys in a previous study (Nishimoto-Kakiuchi et al. 2018), since most of the early lesions did not include the ovaries in the present study, we concluded that the r-ARSM classification, which focuses on lesions and adhesions of 

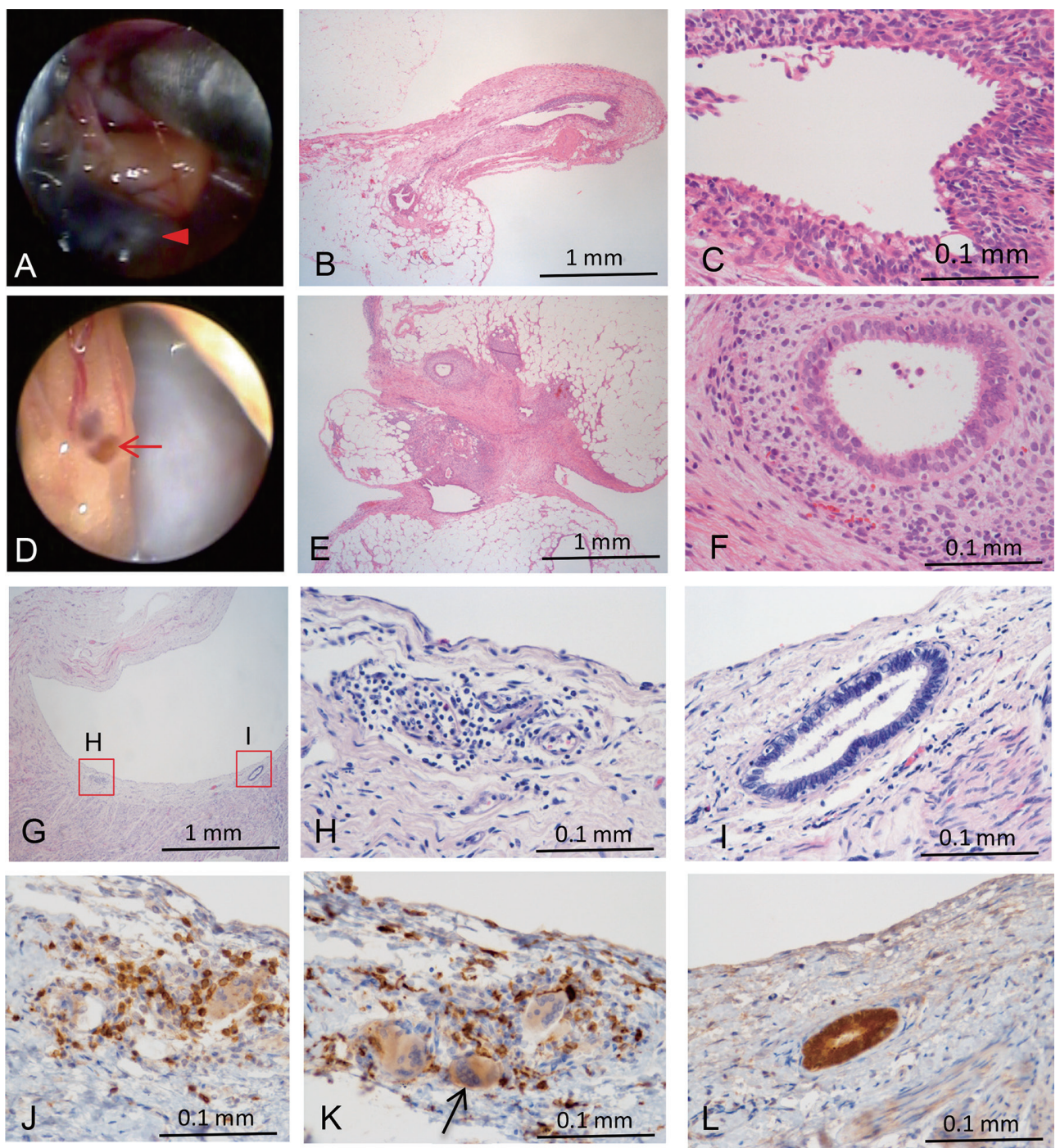

Fig. 5. Histology of endometriosis from an advanced lesion and an early lesion in cynomolgus monkeys.

For an advanced lesion, biopsy was performed from a cyst and a vesicle embedded in the omentum of monkey \#11 one month before the initiation of monthly laparoscopies (A-F). For an early lesion, a tissue was taken from a brown deposition on the peritoneum from the vesicouterine pouch of monkey \#7 that died of acute gastrectasia unrelated to endometriosis two days after the follow-up laparoscopy performed 11 months after the initial laparoscopy (G-L). (A and D) Stationary pictures of a cyst (A) and a vesicle (D). (B and E) Endometrial epithelia, endometrial stroma and fibrosis seen in A and D, respectively $(\times 40)$. ( $C$ and F) Higher magnifications of $B$ and $E$, respectively $(\times 400)$. A stationary picture of the endometriotic lesion from monkey \#7 is shown in Fig. 2D. (G) Inflammation and an endometrial gland were seen in the peritoneum of the tissue $(\times 40)$. $(\mathrm{H})$ Higher magnification of $\mathrm{G}$ shows infiltration of mononuclear cells $(\times 400)$. (I) Higher magnification of $\mathrm{G}$ shows an endometrial gland $(\times 400)$. (J) CD3-positive lymphocytes $(\mathrm{T}$ cells) seen in the same location of $\mathrm{H}$ in a serial section $(\times 400)$. (K) CD163-positive macrophages and macrophage-derived foreign body multinucleated giant cells (arrow) seen in the same location of $\mathrm{H}$ in a serial section $(\times 400)$. (L) Expression of estrogen receptor alpha of an endometrial gland seen in the same location of I in a serial section $(\times 400)$. B, C, E, F, G, H, and I (H \& E staining); J, K, and L (Immunohistochemistry).

the ovaries due to the favorite anatomical sites in humans, could not be directly applied. We also found that it was difficult to assess deep lesions in monkeys that are considered to be at least $5 \mathrm{~mm}$ beyond the surface of the peritoneum in humans. Our purpose was to follow the spatiotemporal development of the disease in cynomolgus monkeys and we successfully monitored the development by mapping endometriotic lesions and adhesions in detail.

Secondly, since the effect of monthly laparoscopies on endometriosis is not known, it is possible that repeated laparoscopies affected the disease development. However, considering that the scores for endometriotic lesions and adhesions did not change for 22 and 17 months, respectively, in monkey $\# 1$, and 17 and 14 months, respectively, in monkey \#2 (Tables 4,5), the effect of laparoscopy on disease development might be minimal.

To our knowledge, our study is the first report to reveal the natural history of spontaneously occurred endometriosis 
in cynomolgus monkeys by mapping endometriotic lesions and adhesions up to two years. Laparoscopic observation in monkeys was useful to study early lesions of endometriosis in the vesicouterine pouch and to detect the appearance of de novo lesions and the disappearance of small lesions. The detailed mapping and quantification of endometriotic lesions and adhesions showed that the progression rate was highly variable among individuals, which closely resembled the heterogeneous clinicopathology in humans. The heterogeneity of the natural history of endometriosis in cynomolgus monkeys could be attributed to the degree or frequency of retrograde menstruation and genetic factors; these findings support the similarities between humans and monkeys, thus verifying the value of this nonhuman primate model. In humans, it is impossible not only to experimentally test therapeutic interventions but also to frequently repeat laparoscopy only for the purpose of quantifying endometriosis. Thus, finding noninvasive quantification markers and unravelling the underlying factors in correlation with the spatiotemporal development of the disease using a nonhuman primate model would be useful for the better management of endometriosis in humans. Cynomolgus monkeys with spontaneous endometriosis will be used to search for novel markers such as serum cytokines and exosomes to predict disease progression, and efficacy of therapeutic intervention will be assessed.

\section{Author Contributions}

K.H., C.I. and H.T. acquired data. K.H., M.N., C.I. and H.T. analyzed data. K.H., M.N., Y.I. and K.O. wrote the manuscript and prepared figures. K.H., M.N., H.T., S.N., K.N., Y.I., S.T., H.I., Takahide M., Takashi M. and K.O. participated in study design, interpretation of results and critical discussion. All authors gave final approval of the manuscript.

\section{Acknowledgments}

We thank Takahiro Nakagawa, Ikuo Kawamoto and Iori Itagaki for their assistance in the experiment and animal care. This work was supported by Grants-in-Aid from the Japan Society for the Promotion of Science (JSPS KAKENHI Grant Numbers JP17K11273 and 26640054).

\section{Conflict of Interest}

The authors declare no conflict of interest.

\section{References}

Afshar, Y., Hastings, J., Roqueiro, D., Jeong, J.W., Giudice, L.C. \& Fazleabas, A.T. (2013) Changes in eutopic endometrial gene expression during the progression of experimental endometriosis in the baboon, Papio anubis. Biol. Reprod., 88, 44.

Ami, Y., Suzaki, Y. \& Goto, N. (1993) Endometriosis in cynomolgus monkeys retired from breeding. J. Vet. Med. Sci., 55, 7-11.

Assaf, B.T. \& Miller, A.D. (2012) Pleural endometriosis in an aged rhesus macaque (Macaca mulatta): a histopathologic and immunohistochemical study. Vet. Pathol., 49, 636-641.

Bizzarri, N., Remorgida, V., Leone Roberti Maggiore, U., Scala, C.,
Tafi, E., Ghirardi, V., Salvatore, S., Candiani, M., Venturini, P.L. \& Ferrero, S. (2014) Dienogest in the treatment of endometriosis. Expert Opin. Pharmacother., 15, 1889-1902.

Braundmeier, A.G. \& Fazleabas, A.T. (2009) The non-human primate model of endometriosis: research and implications for fecundity. Mol. Hum. Reprod., 15, 577-586.

Bulun, S.E. (2009) Endometriosis. N. Engl. J. Med., 360, 268-279.

Cornillie, F.J., D’Hooghe, T.M., Bambra, C.S., Lauweryns, J.M., Isahakia, M. \& Koninckx, P.R. (1992) Morphological characteristics of spontaneous endometriosis in the baboon (Papio anubis and Papio cynocephalus). Gynecol. Obstet. Invest., 34, 225-228.

D’Hooghe, T.M., Bambra, C.S., Cornillie, F.J., Isahakia, M. \& Koninckx, P.R. (1991) Prevalence and laparoscopic appearance of spontaneous endometriosis in the baboon (Papio anubis, Papio cynocephalus). Biol. Reprod., 45, 411-416.

D'Hooghe, T.M., Bambra, C.S., Isahakia, M. \& Koninckx, P.R. (1992) Evolution of spontaneous endometriosis in the baboon (Papio anubis, Papio cynocephalus) over a 12-month period. Fertil. Steril., 58, 409-412.

D'Hooghe, T.M., Bambra, C.S., Raeymaekers, B.M. \& Koninckx, P.R. (1996) Serial laparoscopies over 30 months show that endometriosis in captive baboons (Papio anubis, Papio cynocephalus) is a progressive disease. Fertil. Steril., 65, 645-649.

D’Hooghe, T.M., Kyama, C.M., Chai, D., Fassbender, A., Vodolazkaia, A., Bokor, A. \& Mwenda, J.M. (2009) Nonhuman primate models for translational research in endometriosis. Reprod. Sci., 16, 152-161.

Duffy, D.M. \& VandeVoort, C.A. (2011) Maturation and fertilization of nonhuman primate oocytes are compromised by oral administration of a cyclooxygenase-2 inhibitor. Fertil. Steril., 95, 1256-1260.

Eddy, C.A. \& Laufe, L.E. (1983) Fertility following microsurgical dissociation of the ovary and fimbria in the rhesus monkey. Fertil. Steril., 39, 566-568.

Gruenwald, P. (1942) Origin of endometriosis from the mesenchyme of the celomic walls. Am. J. Obstet. Gynecol., 44, 470-474.

Gylfason, J.T., Kristjansson, K.A., Sverrisdottir, G., Jonsdottir, K., Rafnsson, V. \& Geirsson, R.T. (2010) Pelvic endometriosis diagnosed in an entire nation over 20 years. Am. J. Epidemiol., 172, 237-243.

Hanada, T., Tsuji, S., Nakayama, M., Wakinoue, S., Kasahara, K., Kimura, F., Mori, T., Ogasawara, K. \& Murakami, T. (2018) Suppressive regulatory $\mathrm{T}$ cells and latent transforming growth factor-beta-expressing macrophages are altered in the peritoneal fluid of patients with endometriosis. Reprod. Biol. Endocrinol., 16, 9.

Hester, K.E., Harper, M.J. \& Duffy, D.M. (2010) Oral administration of the cyclooxygenase-2 (COX-2) inhibitor meloxicam blocks ovulation in non-human primates when administered to simulate emergency contraception. Hum. Reprod., 25, 360-367.

Hoshiai, H., Ishikawa, M., Sawatari, Y., Noda, K. \& Fukaya, T. (1993) Laparoscopic evaluation of the onset and progression of endometriosis. Am. J. Obstet. Gynecol., 169, 714-719.

Jimbo, H., Hitomi, Y., Yoshikawa, H., Yano, T., Momoeda, M., Sakamoto, A., Tsutsumi, O., Taketani, Y. \& Esumi, H. (1997) Evidence for monoclonal expansion of epithelial cells in ovarian endometrial cysts. Am. J. Pathol., 150, 1173-1178.

Khan, K.N., Masuzaki, H., Fujishita, A., Kitajima, M., Sekine, I. \& Ishimaru, T. (2004) Differential macrophage infiltration in early and advanced endometriosis and adjacent peritoneum. Fertil. Steril., 81, 652-661.

Kittivanichkul, D., Watanabe, G., Nagaoka, K. \& Malaivijitnond, S. (2016) Changes in bone mass during the perimenopausal transition in naturally menopausal cynomolgus monkeys. Menopause, 23, 87-99. 
Koninckx, P.R., Meuleman, C., Demeyere, S., Lesaffre, E. \& Cornillie, F.J. (1991) Suggestive evidence that pelvic endometriosis is a progressive disease, whereas deeply infiltrating endometriosis is associated with pelvic pain. Fertil. Steril., 55, 759-765.

Kyama, C.M., Mihalyi, A., Chai, D., Simsa, P., Mwenda, J.M. \& D'Hooghe, T.M. (2007) Baboon model for the study of endometriosis. Womens Health (Lond), 3, 637-646.

Maronpot R.R. (1999) Pathology of the mouse, 1st ed., Cache River Press, USA.

Møller, H.J. (2012) Soluble CD163. Scand. J. Clin. Lab. Invest., 72, 1-13.

Nabeshima, H., Murakami, T., Yoshinaga, K., Sato, K., Terada, Y. \& Okamura, K. (2003) Analysis of the clonality of ectopic glands in peritoneal endometriosis using laser microdissection. Fertil. Steril., 80, 1144-1150.

Nakayama, M., Shichinohe, S., Itoh, Y., Ishigaki, H., Kitano, M., Arikata, M., Pham, V.L., Ishida, H., Kitagawa, N., Okamatsu, M., Sakoda, Y., Ichikawa, T., Tsuchiya, H., Nakamura, S., Le, Q.M., et al. (2013) Protection against H5N1 highly pathogenic avian and pandemic (H1N1) 2009 influenza virus infection in cynomolgus monkeys by an inactivated H5N1 whole particle vaccine. PLoS One, 8, e82740.

Nishimoto-Kakiuchi, A., Netsu, S., Matsuo, S., Hayashi, S., Ito, T., Okabayashi, S., Yasmin, L., Yuzawa, K., Kondoh, O., Kato, A., Suzuki, M., Konno, R. \& Sankai, T. (2016) Characteristics of histologically confirmed endometriosis in cynomolgus monkeys. Hum. Reprod., 31, 2352-2359.

Nishimoto-Kakiuchi, A., Netsu, S., Okabayashi, S., Taniguchi, K., Tanimura, H., Kato, A., Suzuki, M., Sankai, T. \& Konno, R. (2018) Spontaneous endometriosis in cynomolgus monkeys as a clinically relevant experimental model. Hum. Reprod., 33, 1228-1236.

Nisolle, M. \& Donnez, J. (1997) Peritoneal endometriosis, ovarian endometriosis, and adenomyotic nodules of the rectovaginal septum are three different entities. Fertil. Steril., 68, 585-596.

O'Connell, G.C., Tennant, C.S., Lucke-Wold, N., Kabbani, Y., Tarabishy, A.R., Chantler, P.D. \& Barr, T.L. (2017) Monocytelymphocyte cross-communication via soluble CD163 directly links innate immune system activation and adaptive immune system suppression following ischemic stroke. Sci. Rep., 7, 12940.

Olive, D.L. \& Pritts, E.A. (2001) Treatment of endometriosis. N. Engl. J. Med., 345, 266-275.

Sampson J.A. (1927) Peritoneal endometriosis due to the menstrual dissemination of endometrial tissue into the peritoneal cavity. Am. J. Obstet. Gynecol., 14, 422-469.

Simmons, H.A. (2016) Age-associated pathology in rhesus macaques (Macaca mulatta). Vet. Pathol., 53, 399-416.

Story, L. \& Kennedy, S. (2004) Animal studies in endometriosis: a review. ILAR J., 45, 132-138.

Yamanaka, A., Kimura, F., Takebayashi, A., Kita, N., Takahashi, K. \& Murakami, T. (2012) Primate model research for endometriosis. Tohoku J. Exp. Med., 226, 95-99. 